\title{
Inferring Density from Temperature via a Density-Ratio Relation
}

\author{
R. H. KÄSE AND H.-H. HINRICHSEN \\ Institut für Meereskunde an der Universität Kiel, Kiel, Germany \\ T. B. SANFORD \\ Applied Physics Laboratory and School of Oceanography, University of Washington, Seattle, Washington
}

(Manuscript received 31 May 1995, in final form 10 May 1996)

\begin{abstract}
A method is presented for determining salinity and density from temperature data in conjunction with historical or contemporaneous (but not collocated) CTD observations. The horizontal density ratio $r(z)$ is determined from the temperature and salinity differences at each depth $(\delta T, \delta S)$ between pairs or ensembles of profiles. These differences are expressed as a density ratio $r=\alpha \delta T / \beta \delta S$, where $\alpha$ and $\beta$ are the expansion coefficients for temperature and salinity, respectively. Salinity at a site where only temperature is measured, as with an expendable bathythermograph (XBT), is computed based on the temperature and salinity at a reference station $\left(S_{R}, T_{R}\right)$; that is, $S=S_{R}+\left(T-T_{R}\right) \delta S / \delta T$. The method is restrictive in its application because it is most accurate when all water masses in the region of a survey are linear extrapolations from the water masses at each of the reference stations. In reality, it provides useful results when the $T$ and $S$ fields are not simply linear functions of horizontal distance. This approach is particularly useful in regions where the $T(z)-S(z)$ relation is nonunique, as in the Mediterranean Water in the North Atlantic. The corresponding expression for the lateral density difference for an observed temperature difference $(\delta T)$ is $\delta \rho=-\alpha \rho_{0} \delta T\left(1-r^{-1}\right)$. Observations from regions offshore and along the coast of Portugal are used to evaluate the method. Errors of less than 0.05 psu are exhibited in the evaluation of salinity determined from T-5 XBT drops compared with nearly simultaneous CTD casts. A comparison of water properties and cyclostrophic velocities is made using XCP temperatures and XCP velocities in a meddy.
\end{abstract}

\section{Introduction}

The expendable bathythermograph (XBT) is a useful instrument for measuring subsurface temperature distributions, particularly from ships of opportunity in less studied regions. Also, rapid surveys of mesoscale features require the use of expendable instruments. In most cases, the salinity structure is also desired but not directly observed. The determination of salinity or density from temperature-versus-depth data is possible only in well-known and stable oceanic regimes. Within some regions, such as one strongly influenced by the Mediterranean outflow, there is no well-defined or unique relationship between temperature and salinity throughout the water column.

Several methods have been used to estimate salinity without direct measurement. Sverdrup et al. (1942) introduced the straight-line $T-S$ representation using end points of $8^{\circ} \mathrm{C}, 35.1 \mathrm{psu}$ and $19^{\circ} \mathrm{C}, 36.7 \mathrm{psu}$ for the North

Corresponding author address: Dr. Thomas B. Sanford, Applied Physics Laboratory, University of Washington, 1013 NE 40th Street, Seattle, WA 98105-6698.

E-mail: sanford@apl.washington.edu
Atlantic Central Water. Water of intermediate temperature is assumed to have a salinity that falls on the straight line. Emery and Dewar (1982) published vertical profiles of salinity and mean $T-S$ diagrams for $5^{\circ}$ squares in the North Atlantic and North Pacific Oceans from historical observations. This method was developed to compute dynamic height from XBT profiles. In regions with mesoscale variability and water mass conversions, this method can produce errors greater than 1 psu. Schmitt (1981) proposed a method based on a constant vertical density ratio for the central water masses of the world's oceans. He claims this representation is superior to the linear $T-S$, such as that used by Sverdrup et al. (1942).

The salinity-depth method of Emery and Dewar (1982) is not suitable for regions where there are large anomalies. The $T-S$ method of Sverdrup et al. fails in situations where the $T-S$ relation is convoluted with no unique correspondence between temperature and salinity.

We have developed a method that takes advantage of the smooth variations of $T$ and $S$ over distance at a constant pressure. Using the observed horizontal distributions of $T(z)$ and $S(z)$, it is possible to compute a salinity profile at a local site when given only $T(z)$. 
It is most appropriate for a property field that changes smoothly and monotonically between CTD stations, as in the case of water mixed from common sources. This method provides a way to determine salinity from XBT drops, such as those used in synoptic surveys of mesoscale features, by using as few as two horizontally separated CTD profiles. The method's accuracy depends not only on the amount and distribution of the CTD profiles, but also on the errors in the XBT data. In particular, errors in estimating the fall rate of the XBTs can introduce errors in the computation of salinity (Boyd and Linzell 1993).

A motivation for this work is that dynamic computations depend on lateral differences in density. The proposed method establishes a means for determining the lateral differences based on a few CTD casts and numerous XBT profiles.

Finally, the method supports the interpretation of $\mathrm{XBT}$ lines in terms of meso- and large-scale circulation and the initialization of numerical models.

\section{Methods}

A set of horizontally spaced CTD stations can be used to define a relationship between $T$ and $S$, as shown in Fig. 1. In the simplest case, a pair of adjacent stations with different water properties ( say, $T_{1}, T_{2}$ and $S_{1}, S_{2}$ ) determines a line of slope $r$ in the $\alpha T-\beta S$ plane, with $r$ defined as

$$
r=\frac{\alpha \delta T}{\beta \delta S},
$$

where $\alpha$ and $\beta$ are the expansion coefficients for temperature and salinity (McDougall 1987):

$$
\alpha=-\frac{1}{\rho} \frac{\partial \rho}{\partial T}
$$

and

$$
\beta=\frac{1}{\rho} \frac{\partial \rho}{\partial S},
$$

which are functions of $S, T$, and $p$; and $\delta T$ and $\delta S$ are, respectively, the horizontal differences of temperature and salinity at the same depth over the distance $\delta x$. Here $\delta S / \delta T$ are computed from a single station pair (such as $T_{1}, T_{2}$ and $S_{1}, S_{2}$ ) or (more commonly) averages of stations near the end members of the water masses of the survey region. Because of the assumed linearity of the $T$ and $S$ fields, the direction of $\delta x$ does not matter, although errors in the computation of $r$ may increase for small values of $\delta S$ and $\delta T$. It is important to obtain CTD profiles across the main variability in the survey region, such as between the core of an eddy and the surrounding water.

If the distribution of $r$ is uniform, it is a function of depth only, and salinity $S$ from a temperature profile $T$ is computed as

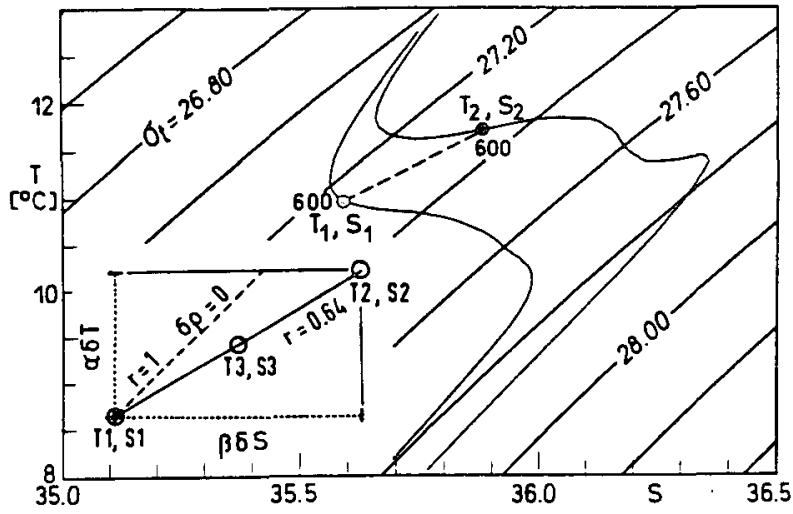

FIG. 1. The $T-S$ diagram for two CTD profiles. Profile 1 (left) is the reference profile and profile 2 (right) is one that exhibits large differences from the reference profile. The method assumes that the temperature and salinity $\left(T_{3}, S_{3}\right)$ at a given depth, say $600 \mathrm{~m}$, from any profile will lie on the line connecting the points $T_{1}, S_{1}$ and $T_{2}, S_{2}$. The inset introduces the horizontal density ratio $r$ as the slope of the line between $T_{1}, S_{1}$ and $T_{3}, S_{3}$ in the fractional density coordinates of $-\alpha \delta T, \beta \delta S$.

$$
S=S_{R}+\left(T-T_{R}\right) \frac{\delta S}{\delta T},
$$

where $S_{R}$ and $T_{R}$ are from a reference CTD profile, such as the nearest one.

To calculate geostrophic currents, only the horizontal density differences are required. This information comes directly from a linearized equation of state with $\rho=\rho_{0}$, a constant, except when differentiated:

$$
\frac{\delta \rho}{\rho_{0}}=-\alpha \delta T+\beta \delta S .
$$

Insertion of (1) into (3) yields an expression for the density difference $\delta \rho$ in terms of an observed temperature difference $(\delta T)$ and $r$ :

$$
\delta \rho=-\alpha \rho_{0} \delta T\left(1-r^{-1}\right) .
$$

This expression for density can be used to compute geostrophic velocity according to the relation

$$
\frac{\partial v_{g}}{\partial z}=-\left(\frac{g \rho_{0} \alpha}{f}\right) T_{x}\left(1-r^{-1}\right),
$$

where $g$ is the acceleration of gravity, $f$ is the Coriolis parameter, and $T_{x}$ is the horizontal temperature gradient (i.e., $\delta T / \delta x$ ).

Assuming $r$ is representative of the region of measurement and can be applied to individual temperature profiles, one can obtain salinity and density from XBT data. In some cases, the $r$ profile should be vertically filtered to scales larger than $50-100 \mathrm{~m}$ to remove internal-wave and small-scale variability. Another approach is to obtain several CTD profiles to use as the reference stations. Either method yields a representa- 
tive $r$ profile for the region of interest on vertical scales of $25 \mathrm{~m}$ or larger.

There are restrictions in the use of this method.

1) There should be no intrusions of distinct water of different origin (in which another $r$ obtains).

2) The $r$ value has to be based on sufficiently different CTD profiles so as to be robust.

$3)$ The difference density (i.e., $\delta \rho$ ) must be represented by a linear approximation; only small excursions from the reference profile are suitable (typically $\delta \rho$ $<0.1 \mathrm{~kg} \mathrm{~m}^{-3}$ over $20 \mathrm{~km}$ ) ; thus, cabbeling effects must be unimportant.

It should be noted that the horizontal density ratio is distinct from the vertical density ratio introduced in studies of double diffusion instability such as those by Stern and Turner (1969). This ratio is defined for the salt-fingering regime as $R \rho:=\alpha T_{z} / \beta S_{z}$, where $T_{z}$ and $S_{z}$ are the vertical gradients temperature and salinity, respectively. This definition of density ratio based on vertical gradients of $T$ and $S$ is related to our density ratio formed from horizontal property gradients by the slopes of the $T$ and $S$ isolines (i.e., $z_{T} / z_{S}$ ):

$$
r(z)=R_{\rho}^{\prime} \frac{z_{T}}{z_{S}}
$$

\section{Results}

The method was applied to $T$ and $S$ profiles from the eastern North Atlantic off the coast of Portugal. On two cruises, we measured water properties and velocities in general flow and within mesoscale eddies, called "meddies" for their strong Mediterranean Water content. Measurements taken on FS Poseidon cruise 200/ 9 in summer 1993 determined water properties off the west coast of Portugal. Similar studies were undertaken during R/V Oceanus cruise 202 in autumn 1988. The boxes in Fig. 2 show the regions where data were obtained during these cruises.

The mean $r(z)$ for box A is plotted in Fig. 3a with standard deviations. For this calculation, 49 CTD stations were used, of which 13 were contributed by the Poseidon cruise. Above $400 \mathrm{~m}$, density changes in this region of North Atlantic Central Water are produced more by temperature variations than by salinity. Below $400 \mathrm{~m}$, the opposite holds, with salinity being more important, except for a small region near $900 \mathrm{~m}$ where the horizontal $T$ and $S$ variations produce equal density contributions. The $r$ profile was used with the CTD stations of box A to compute salinity based only on CTD temperature. This estimated salinity was then compared with the salinity observed on the 13 simultaneous Poseidon CTD casts. The linear regression coefficient was 0.998 with an intercept of 34.993 psu at an observed salinity of $35.0 \mathrm{psu}$. The residuals, plotted in Fig. 3b, have an rms value of 0.023 psu. The principal error in this comparison is in the determination of

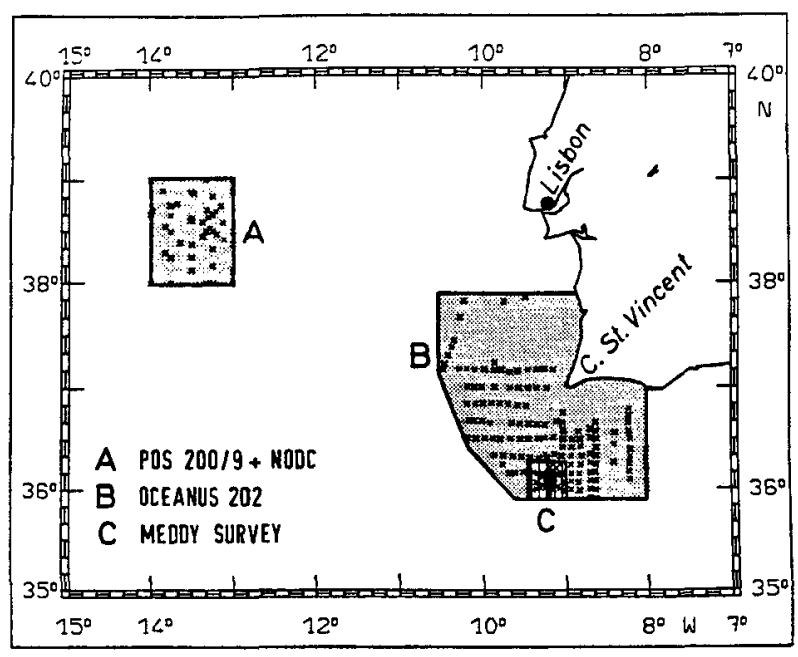

FIG. 2. Chart of the locations of observations used in this study. Box A contains mainly CTD stations obtained from NODC, supplemented by a few taken during Poseidon 200/9 in the summer of 1993. Box B contains XBT, XCP, and CTD stations taken during Oceanus 202 in the fall of 1988 plus additional CTD stations obtained from NODC. No distinction is made in this figure between $\mathrm{XBT}, \mathrm{XCP}$, and CTD stations; most sites are XBT only. Box C contains stations taken in a small-scale feature, called the meddy.

$r(z)$; temperature errors in the CTD sensor are negligible. In this case, the error in salinity can be derived from (1) and is of the form

$$
\Delta(\delta S)=-\delta S \frac{\Delta r}{r},
$$

where $\Delta r$ is the error in $r$ at a given depth and $\Delta(\delta S)$ is the resulting salinity error. For an error in $r$ of 0.1 , a mean $r$ of order unity, and a salinity deviation from the reference station of $0.5 \mathrm{psu}$, the salinity error is about $0.05 \mathrm{psu}$. This is an order of magnitude or more larger than high quality CTD measurements of salinity. A deviation of 0.1 psu over a $100-\mathrm{m}$ vertical interval at a constant temperature produces a dynamic height error of $0.08 \mathrm{~J} \mathrm{~kg}^{-1}$. Such systematic errors contribute significant density and dynamic height errors.

The region of box $\mathrm{A}$ is characterized by large-scale variations in water properties, caused in part by the presence of warm, salty Mediterranean Water entering the North Atlantic and a large $(>60 \mathrm{~km})$ meddy, an eddy containing high concentrations of Mediterranean Water in its core.

Box B in Fig. 2 is in the Mediterranean Water undercurrent adjacent to the coast of Portugal. The data for this region were obtained from the National Oceanographic Data Center (NODC) and include both historical observations and those from the quasi-synoptic survey conducted during Oceanus 202. Within this region, there are some examples from Oceanus 202 of CTD and XBT observations taken less than $2 \mathrm{~h}$ apart. Figure 4 compares two CTD-XBT profiles (a), shows 

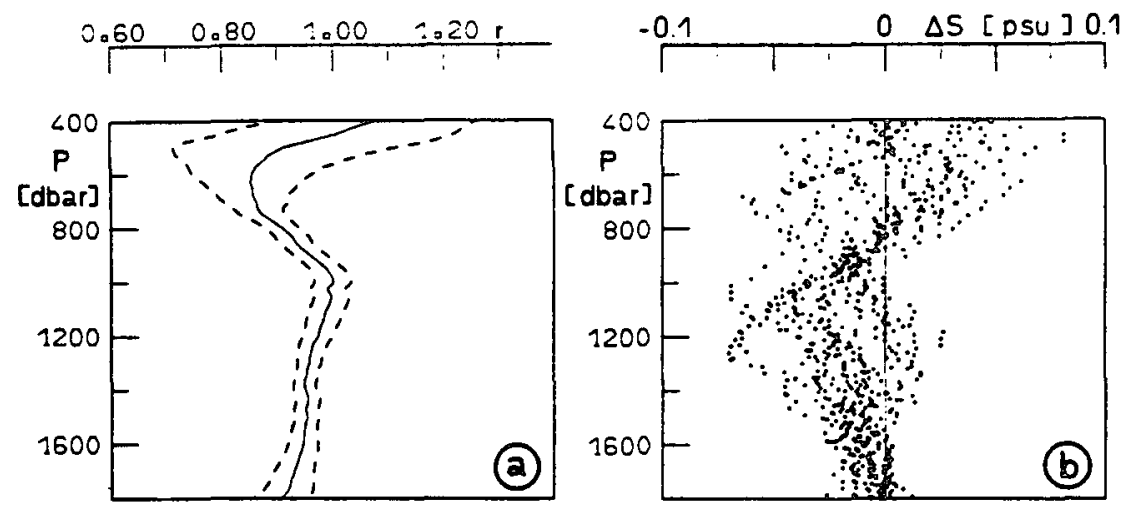

FIG. 3. (a) Profile of horizontal density ratio for box A in Fig. 2. The mean profile is shown as a solid line with one standard deviation about the mean shown as dashed lines. (b) Profiles of $S_{\text {est }}-S_{\text {obs }}$ for the CTD stations in box A. The CTD temperature was used with the $r$ relation to compute $S_{\text {est }}$, which was then compared with the salinity computed from the combination of temperature, electrical conductivity, and pressure observed by the CTD $\left(S_{\mathrm{obs}}\right)$.

the mean $r(z)$ calculated for all CTD stations from the NODC dataset (b), and compares the estimated salinities with the observed (CTD) salinities (c). The temperature profiles in Fig. 4 a exhibit differences contributed by both ocean variability and measurement errors of the XBT. The XBT measurement has temperature errors of $0.1^{\circ} \mathrm{C}$ and random and systematic depth errors of about $2 \%$ of full scale, especially below $1000 \mathrm{~m}$. The horizontal density ratio is similar to that shown in
Fig. $3 \mathrm{~b}$ for box A, but with standard deviations about half as large. There are two reasons for this. First, the magnitudes of the salinity variations in box $\mathrm{A}$ are smaller, about half as large as closer to the coast. Second, the waters nearer Portugal are various mixtures of the principal end products, namely, North Atlantic Central Water and Mediterranean Water, producing horizontal density ratios that are nearly laterally uniform. The differences in salinity near the salinity minimum
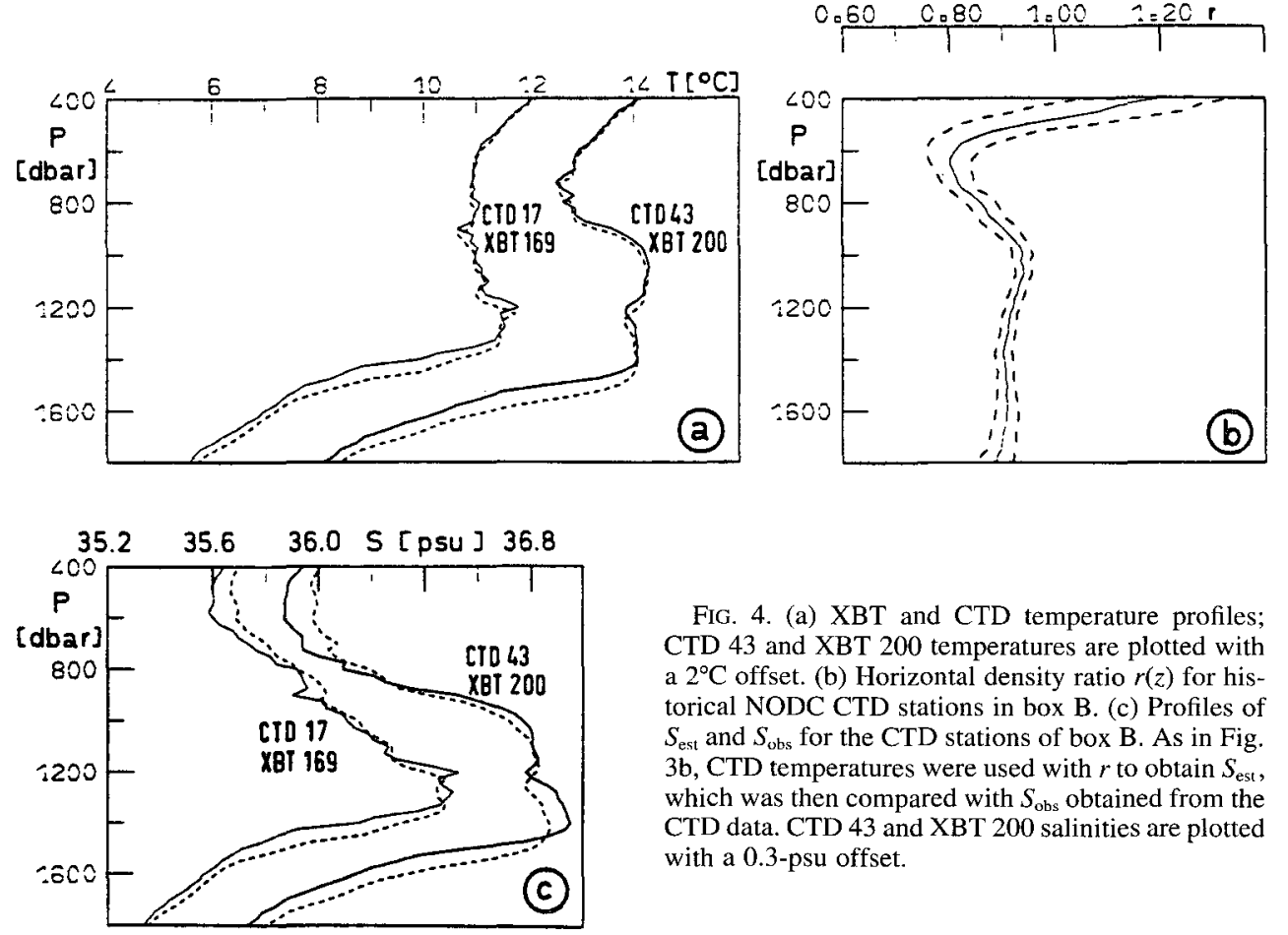

FIG. 4. (a) XBT and CTD temperature profiles; CTD 43 and XBT 200 temperatures are plotted with a $2^{\circ} \mathrm{C}$ offset. (b) Horizontal density ratio $r(z)$ for historical NODC CTD stations in box B. (c) Profiles of $S_{\text {est }}$ and $S_{\text {obs }}$ for the CTD stations of box B. As in Fig. $3 \mathrm{~b}$, CTD temperatures were used with $r$ to obtain $S_{\text {est }}$, which was then compared with $S_{\text {obs }}$ obtained from the CTD data. CTD 43 and XBT 200 salinities are plotted with a 0.3 -psu offset. 
at $500 \mathrm{~m}$ (Fig. 4c) must result mainly from variability in $r$ because the observed temperature differences (Fig. $4 a)$ in this region are small. Near the Mediterranean Water core, the salinity differences again are caused by errors in $r$. Deeper in the water column, the salinity differences appear to result from depth and temperature errors of the T-5 XBTs. An improvement could be obtained here by applying a regional calibration for the $\mathrm{T}-5$ fall rate based on minimization of the temperature differences between the T-5 XBT and CTD profiles (Prater 1991).

It should be emphasized that these salinities were obtained by applying a regional mean $r(z)$. The salinity estimation can be improved by applying an $r(z)$ based on a more localized and synoptic set of CTD stations. Such a computation is undertaken next for the case of an individual meddy.

During Oceanus 202 a regional, eddy-resolving XBT survey was conducted off the SW coast of Portugal (box $\mathrm{C}$ in Fig. 2). The salinity field calculated at $1000 \mathrm{db}$ using the $r(z)$ of Fig. $4 \mathrm{~b}$ is presented in Fig. $5 a$; it exhibits the characteristic structure of the Mediterranean outflow near the coast and the isolated meddies offshore. The water saltier than 36.2 psu and inshore of that isohaline is typical of the Mediterranean outflow (Wüst 1935). This region exhibits the continuous, ribbonlike flow of the main Mediterranean outflow with considerable meandering and eddies being formed. There are three major features inshore of the main Mediterranean flow with salinities greater than 36.4 psu. Within the Mediterranean outflow, there is a possible meddy being formed south of Cape St. Vincent. In addition, there are three offshore features with salinities greater than 36.3 psu that are identified as meddies. The middle one, near $36^{\circ} \mathrm{N}, 9^{\circ} \mathrm{W}$, was chosen for a detailed survey (Prater 1992; Prater and Sanford
1994). Figure $5 \mathrm{~b}$ is the dynamic height field at 1000 $\mathrm{db}$ relative to $1500 \mathrm{db}$. The pattern is shifted slightly relative to Fig. $5 \mathrm{a}$ in most features, with the highs and lows of dynamic height being displaced relative to the salinity features. This is because the local dynamic height arises from the vertical integral of density. In some of the cases, the vertical variation of perturbation density is of variable sign and partially cancels. Note that the region in the northeast corner contains no contours because the water is shallower than $1500 \mathrm{~m}$, preventing the computation of the dynamic height.

The pattern of salinity and dynamic height shown in Fig. 5 compares well with historical observations. This example illustrates how the method is able to estimate salinity from temperature in a region with a complex, nonunique $T-S$ relation. Usually, no attempt is made to estimate salinity for these reasons, but the application of the horizontal density ratio provides a means for doing this.

Another use of this method is in rapid surveys of selected features with few CTD casts but many XBT profiles. An example is the survey of the isolated feature identified earlier as the meddy near $36^{\circ} \mathrm{N}, 9^{\circ} \mathrm{W}$. In this survey, $29 \mathrm{~T}-5 \mathrm{XBT}$ profiles and 7 CTD profiles were obtained. The XBT profiles were distributed along six radial legs, and the CTD profiles were distributed with four at cardinal points outside the meddy and three near the center. Figure 6a presents the $r$ profile for the seven CTD stations, and Fig. $6 \mathrm{~b}$ shows the derived salinity and computed cyclostrophic velocity fields at $1000 \mathrm{db}$. The size and strength of this meddy require that the gradient wind, or cyclostrophic balance, be used to compute the velocities. There are deviations from circular symmetry, especially evident in the southern limb of the meddy. This gives rise to speeds larger than the typical values of $0.2 \mathrm{~m} \mathrm{~s}^{-1}$.
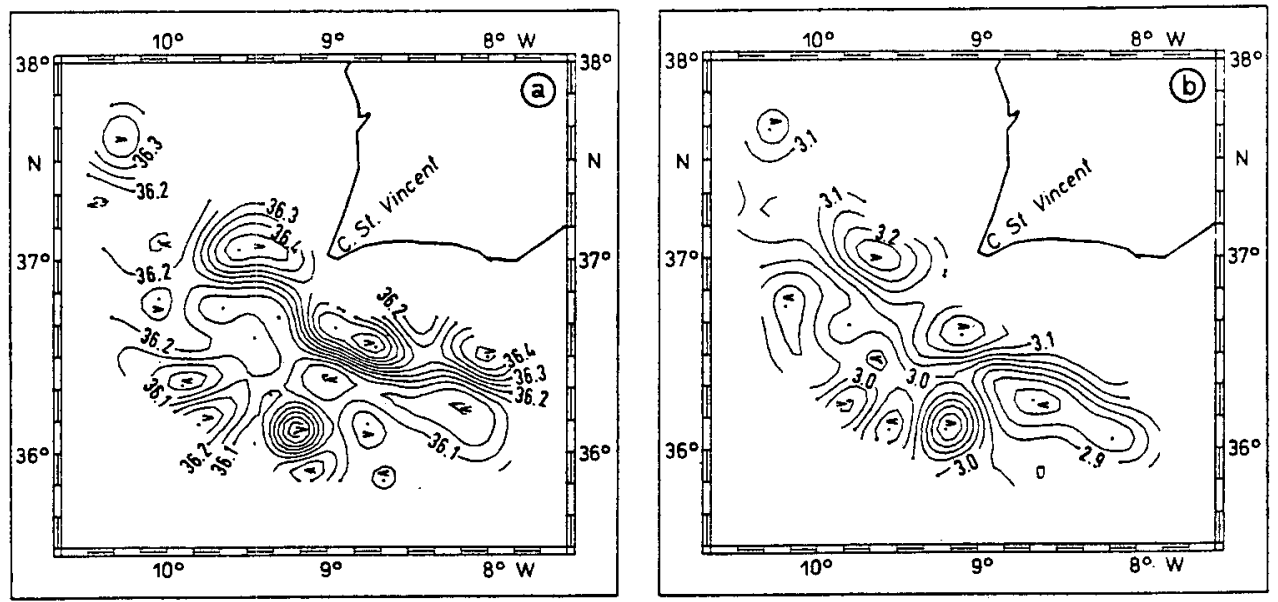

FIG. 5. (a) Contour map of salinity at $1000 \mathrm{db}$ in box B calculated by the $r$ method using only observations from Oceanus 202. Objective analysis was used with an isotropic, Gaussian covariance function with an $e$ folding scale of $20 \mathrm{~km}$. Contour interval is $0.05 \mathrm{psu}$. (b) Contour map of dynamic height $\left(\mathrm{J} \mathrm{kg}^{-1}\right)$ at $1000 \mathrm{db}$ relative to $1500 \mathrm{db}$, based on observed temperature and computed salinity. The contour interval is $0.05 \mathrm{~J} \mathrm{~kg}^{-1}$. 


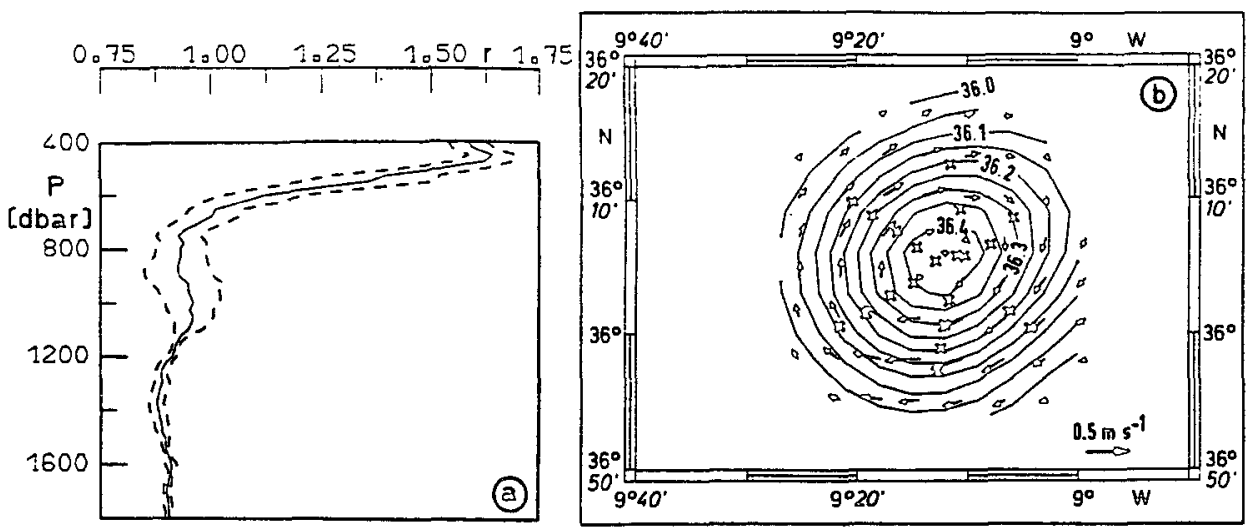

FIG. 6. (a) Profile of $r(z)$ in box $C$ based on four CTD casts outside of and three in the center of the meddy. (b) Contours of computed salinity at $1000 \mathrm{db}$ from objective analysis using an isotropic, Gaussian covariance function with an $e$-folding scale of $20 \mathrm{~km}$. Contours are shown every $0.05 \mathrm{psu}$ and only when errors are smaller than $40 \%$ of the variance. Cyclostrophic velocity vectors are shown at $1000 \mathrm{db}$.

A more detailed comparison of cyclostrophic velocities with directly measured velocities is available for this meddy. At each XBT site in the meddy, an XCP was also deployed. The XCP is an expendable electromagnetic velocity (current) and temperature profiler that determines a velocity profile to within an unknown offset (Sanford et al. 1982). The density- and XCPderived velocity profiles are relative to unknown constants. The most appropriate comparison is in terms of vertical shear in which the depth-constant offsets are removed. Such a comparison is presented in Fig. 7. Prater and Sanford (1994) describe the meddy as having two distinct cores, the upper centered at $1050 \mathrm{db}$ and the lower at $1350 \mathrm{db}$. The velocity maximum corresponds to a zero crossing of the vertical shear. The upper core has larger velocities and may influence the velocity structure observed in the lower core. It is clear from Fig. 7 that the method is successful in estimating the cyclostrophic velocities from many XBT casts supported by a few CTD casts.

Most XBT observations are obtained along a section, rather than during a mapping survey. A section was obtained during Oceanus 202 off Cape St. Vincent, Portugal, on which nearly simultaneous CTD and XCP profiles were taken. In general, the XCP provides more accurate temperature measurements than the T-5 XBT, especially in deep water where the latter often suffers from electrical leakage in the wires. Figure 8 presents the salinity section derived from the XCP temperature data when using a regionally averaged $r(z)$ calculated from the accompanying CTD profiles. Also shown as shaded regions are the places where the computed salinity is different from the CTD-determined salinity by

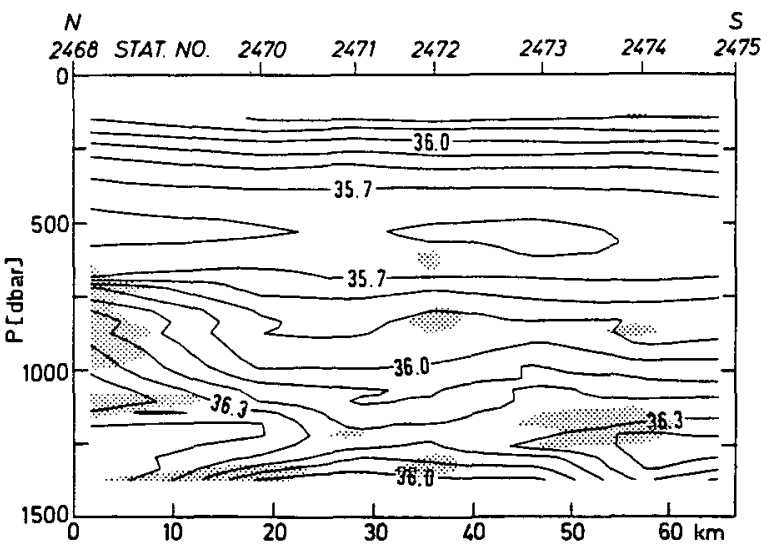

FIG. 8. Contours of salinity computed from XCP temperatures and sectional mean $r(z)$ with shading to indicate regions of error greater than $0.05 \mathrm{psu}$. The line of stations is along $8^{\circ} 37^{\prime} \mathrm{W}$, starting from $36^{\circ} 45.9^{\prime} \mathrm{N}$ on the left and ending at $35^{\circ} 54.4^{\prime} \mathrm{N}$ on the right, corresponding to section 4 of Kennelly et al. (1989).
FIG. 7. Comparison of meddy velocities derived from XCP data with those based on XBT data. Mean shear of XCP profiles (solid line) and XCP-temperature-derived cyclostrophic shear (dashed line) versus pressure at the radius of maximum azimuthal velocity. 
more than 0.05 psu. The largest discrepancies occur close to the Portuguese coast, where the Mediterranean Water content and spatial gradients are high. Natural and sampling variabilities are responsible for most of this error. The nonsimultaneity of the CTD and XCP profiles, for example, contributes to the observed differences. The rms salinity deviations are 0.016 psu.

\section{Conclusions}

The proposed method is based on the reality that water properties change laterally. A $T-S$ relation at one location will be slightly different than that at another. We suggest a method formulated around contemporaneous or historical observations of the horizontal differences of water properties. In essence, the scheme assumes that within the study region any water mass lies along a line in the $T-S$ plane joining points at the same depth on the $T-S$ curves for two reference stations. It will not work well in regions with strong anomalies that have not had time to mix laterally. It does not assume a mechanism for this mixing, but is most appropriate when the mixing can be represented as lateral, or Cartesian, mixing. In most instances, the method is applied over small lateral scales, and the differences between isopycnal and isobaric mixing are small.

Note that the horizontal density ratio $r(z)$ calculated according to $(6)$ is equal to the conventional vertical density ratio $\left(R_{\rho}\right)$ when the horizontal slopes of temperature and salinity are equal. That is, the vertical variations are just projections of those in the horizontal. In addition, when $r(z)$ is vertically constant, the $T-S$ relationship can be equivalently described by $r$ as well as by $R_{\rho}$. However, isotherms and isohalines generally have differing slopes.

The method is applied to a region dominated by the Mediterranean outflow. Contrasts are found between stations in the outflow and in the surrounding water, as well as between stations in the meddies and in the ambient waters. The $T-S$ relations are clearly different in these situations. However, water properties vary rather smoothly between these water masses. Thus, one would expect a water parcel at depth $z$ and temperature $T$ to lie along the line connecting the $T-S$ points at this $z$ with the two contrasting CTD stations. The line defines a density ratio $r(z)$, which is used to analytically determine $S(z)$ from $T(z)$ profiles. This interpolation/extrapolation is depicted in Fig. 1.

This method is applied to XBT observations within a meddy and compared with independent velocity observations. The small scale of the meddy requires that cyclostrophy be applied. The computations confirm the necessity of using cyclostrophy and are in agreement with the XCP velocities.
When the method is applied to a section of nearly simultaneous CTD and XBT profiles taken off Cape St. Vincent, performance improves because of the use of concurrent CTD data for determining $r(z)$.

The method should provide useful results in situations where only a few CTD casts can be obtained or historical temperature and salinity observations must be used. Such situations are common when using XBTs from volunteer observing ships and during rapid, synoptic surveys of ocean features from a ship under way.

Acknowledgments. We would like to thank Gunnar Roden, Knut Aagaard, and Eric Kunze for reading a draft of this manuscript. Also, John Dunlap provided assistance with data processing. A. Schurbohm drafted many of the figures. This research was supported by the Office of Naval Research and the Deutsche Forschungsgemeinschaft through the project Warmwassersphäre des Atlantiks.

\section{REFERENCES}

Boyd, J. D., and R. S. Linzell, 1993: The temperature and depth accuracy of Sippican T-5 XBTs. J. Atmos. Oceanic Technol., $10,128-136$

Emery, W. J., and J. S. Dewar, 1982: Mean temperature-salinity, salinity-depth and temperature-depth curves for the North Atlantic and the North Pacific. Progress in Oceanography, Vol. 11, Pergamon, 219-305.

Kennelly, M. A., J. H. Dunlap, T. B. Sanford, E. L. Kunze, M. D. Prater, and R. G. Drever, 1989: The Gulf of Cadiz Expedition: R/V Oceanus Cruise 202. Tech. Rep. APL-UW TR 8914, 115 pp. [Available from the Applied Physics Laboratory, University of Washington, 1013 NE 40th Street, Seattle, WA 98105-6698.]

McDougall, T. J., 1987: Neutral surfaces. J. Phys. Oceanogr., 17, $1950-1964$.

Prater, M. D., 1991: A method for depth and temperature correction of expendable probes. J. Atmos. Oceanic Technol., 8, 888-894. , 1992: Observations and hypothesized generation of a meddy in the Gulf of Cadiz. Tech. Rep. APL-UW TR 9210, $131 \mathrm{pp}$. [Available from the Applied Physics Laboratory, University of Washington, 1013 NE 40th Street, Seattle, WA 98105-6698.]

, and T. B. Sanford, 1994: A meddy off Cape St. Vincent. Part I: Description. J. Phys. Oceanogr,, 24, 1572-1586.

Sanford, T. B., R. G. Drever, J. H. Dunlap, and E. A. D'Asaro, 1982: Design, operation and performance of an expendable temperature and velocity profiler (XTVP). Tech. Rep. APL-UW TR 8110,165 pp. [Available from the Applied Physics Laboratory, University of Washington, $1013 \mathrm{NE}$ 40th Street, Seattle, WA 98105-6698.]

Schmitt, R. W., 1981: Form of the temperature-salinity relationship in the Central Water: Evidence for double-diffusive mixing. $J$. Phys. Oceanogr., 11, 1015-1026.

Stern, M. E., and J. S. Turner, 1969: Salt fingers and convecting layers. Deep-Sea Res., 16, 497-511.

Sverdrup, H. V., M. W. Johnson, and R. H. Fleming, 1942: The Oceans: Their Physics, Chemistry and General Biology. Prentice Hall, 1087 pp.

Wuist, G., 1935: The Stratosphere of the Atlantic Ocean, Vol. 6, Scientific Results of the German Atlantic Expedition of the Research Vessel 'Meteor' 1925-27, Amerind, $112 \mathrm{pp}$. 